\title{
PERCEPÇÃO DE ESTUDANTES DE UMA UNIVERSIDADE PÚBLICA ACERCA DA MONITORIA E TUTORIA DE BIOFÍSICA
}

Perception of students of a public university about the monitoring and tutoring of Biophysics

Percepción de estudiantes de una universidad pública acerca del monitoreo y la tutoria de Biofísica

\section{Jarlan Santana de Souza ${ }^{1}$, Ana Isabel Reis Nascimento ${ }^{2 *}$}

${ }^{1}$ Graduando de Fisioterapia na Universidade Estadual do Sudoeste da Bahia, UESB, campus Jequié.

${ }^{2}$ Doutora em Patologia Humana, Docente Titular do Departamento de Ciências

Biológicas, Universidade Estadual do Sudoeste da Bahia, campus Jequié.

*Correspondência: airnascimento@uesb.edu.br

Artigo recebido em 09/05/2019 aprovado em 19/07/2020 publicado em 31/10/2020.

\section{RESUMO}

A monitoria acadêmica e a tutoria são coadjuvantes na formação de estudantes e funcionam como ferramenta de apoio pedagógico por meio do qual o discente-monitor e o discente-assistido têm oportunidade de aprofundar o conhecimento. Este estudo descreveu a percepção de educandos de uma Universidade pública da Bahia, acompanhados por dois métodos de auxílio à aprendizagem, a monitoria e a tutoria, ofertados por esta instituição. Os dados foram coletados a partir da aplicação de questionário estruturado a 81 monitorandos e 6 tutorandos. A análise estatística foi do tipo descritiva, expressa em frequência absoluta e relativa. A busca pela monitoria e tutoria apresentou-se baixa comprometendo o esclarecimento das dúvidas. Apesar disso, os universitários as reconheceram como métodos importantes para melhor consolidação dos assuntos e desenvolvimento nas disciplinas. Os estudantes que necessitam desses auxílios pedagógicos ficam com acesso limitado pois o universo acadêmico exige atividades extraclasse com extensa carga horária. Isso induz o aluno afirmar prioridade a algumas tarefas, subestimando outras de igual importância para um desempenho acadêmico satisfatório.

Palavras-chave: Monitoria. Tutoria. Biofísica

\section{ABSTRACT}

The academic monitoring and tutoring are coadjuvant in the training of students and function as a pedagogical support tool through which the monitor-student and the assisted-student have the opportunity to deepen their knowledge. This study described the perception of students from a public university in Bahia, accompanied by two methods of aid to learning, monitoring and tutoring, offered by this institution. The data were collected through the application of a structured questionnaire to 81 monitoring and 6 tutoring. The statistical analysis was descriptive, expressed in absolute and relative frequency. The search for monitoring and tutoring was low, compromising the clarification of doubts. Despite this, university students recognized them as important methods for better consolidation of subjects and development in the disciplines. Students who need these educational aids have limited access because the academic universe requires extra-class activities with an extensive workload. This induces the student to affirm priority to some tasks, underestimating others of equal importance for satisfactory academic performance.

Keywords: Monitoring. Tutoring. Biophysics. 


\section{RESUMEN}

El monitoreo académico y la tutoría son coadyuvantes en la formación de los alumnos y funcionan como una herramienta de apoyo pedagógico a través de la cual el monitor-alumno y el alumno asistido tienen la oportunidad de profundizar sus conocimientos. Este estudio describió la percepción de estudiantes de una universidad pública en Bahía, acompañada de dos métodos de ayuda al aprendizaje, monitoreo y tutoría, ofrecidos por esta institución. Los datos fueron recolectados mediante la aplicación de un cuestionario estructurado a 81 estudiantes monitores y 6 tutores. El análisis estadístico fue descriptivo, expresado en frecuencia absoluta y relativa. La búsqueda de monitoreo y tutoría fue baja, comprometiendo la aclaración de dudas. A pesar de esto, los estudiantes universitarios los reconocieron como métodos importantes para una mejor consolidación de materias y desarrollo en las disciplinas. Los estudiantes que necesitan estas ayudas educativas tienen acceso limitado porque el universo académico requiere actividades extra-clase con una gran carga de trabajo. Esto induce al alumno a priorizar algunas tareas, subestimando otras de igual importancia para um desempño académico satisfactorio.

Palabras clave: Monitoreo. Tutoría. Biofísica.

\section{INTRODUÇÃO}

A Biofísica é uma ciência multidisciplinar que examina os fenômenos da vida desde a estrutura mais simples a ecossistemas complexos. Seu estudo teve início no século XIX quando os princípios da Física começaram a ser aplicados nas Ciências Biológicas. Os primeiros grupos de cientistas a fazer uso da Biofísica foram os alemães através de estudos da Radiação e seus efeitos nas células, além disso realizaram estudos das descargas elétricas em células nervosas. No Brasil, a aplicação da Biofísica se deu por meio do pesquisador Carlos Chagas Filho que foi pioneiro nos estudos das descargas elétricas do peixe amazônico Electrophorus eletricus (poraquê da Amazônia) e acabou se especializando em Física Biológica pela Fundação Oswaldo Cruz (LIMA, 2011).

No século XX a Biofísica sofreu uma mudança epistemológica. Os cientistas que se dedicaram ao seu desenvolvimento e sua aplicação foram unânimes ao afirmar que esta ciência não resultava simplesmente da aplicação conjunta da Física e Química à Biologia. Segundo Carlos Chagas Filho a Biofísica se define como "a ciência que estuda os fenômenos biológicos em seus aspectos físico-químicos" (CHAGAS FILHO, 1943: 3). Porém ele salienta que essa definição é imprecisa devido à natureza experimental da aplicação da Biofísica, o que deixa claro uma limitação conceitual quanto ao raio de ação dessa área do conhecimento.

Nas instituições de ensino a disciplina Biofísica é ofertada a diversos cursos da área da saúde. Por isso existem vários currículos adaptados à formação profissional de cada curso (MOREIRA 2018; POPESCU 2002). Os mecanismos físicos de diversos

processos biológicos são instrumentos que norteiam o ensino da Biofísica e para isso requer do estudante conhecimento antecipado da Física Básica (CORSO, 2009). Com isso muitos estudantes apresentam dificuldades nesta área do conhecimento oriundas da Educação Básica, sobretudo em cursos da área de Exatas e Naturais comprometendo, dessa forma, a conexão de conteúdos necessária ao entendimento de disciplinas na graduação (GUIMARÃES, DICKMAN e CHAVES, 2014).

Estudos mostram que a repetência e a evasão no Ensino Superior (EnS) geram prejuízos socioeconômicos, pois são realizados grandes investimentos para sua oferta e tanto o estudante que atrasa a época de sua formatura quanto aquele que cursa parte do currículo e desiste logo após, ocupam vagas que ainda são concorridas (LEAL, 2013). Antes mesmo dessas consequências, são criadas e fortalecidas na academia, desde tempos remotos, monitorias e tutorias 
que funcionam como estratégias para minimizar as dificuldades dos discentes frente às abstrações dos conteúdos ministrados no EnS. (JÚNIOR, BOAS E SOUZA, 2019).

O início da monitoria remonta a diferentes períodos e locais e uma das suas principais raízes é representada pelo período medieval nos séculos $\mathrm{V}$ ao $\mathrm{XV}$, onde o professor escolhia um assunto a ser explicado publicamente pelos alunos e estes apresentavam seus argumentos sobre o tema escolhido (FRISON 2016; GILES 1987). No século XVI os professores passaram a receber auxílios dos melhores alunos, que se tornavam responsáveis por outros colegas de quem tomavam as lições de cor, recolhiam os exercícios e marcavam erros, acertos e faltas diversas (DANTAS 2014; MIRANDA 2009; RIBEIRO 2002).

Esse cenário só mudou no final do século XVIII na Inglaterra quando um novo método de ensino foi criado, o 'Ensino Mútuo ou Monitorial', sistematizado por Andrew Bell e Joseph Lancaster no qual os adolescentes eram instruídos diretamente pelos mestres e atuavam como auxiliares ou monitores. Neste novo método havia orientação a outros adolescentes, supervisão de suas condutas e administração dos materiais didáticos. Esta metodologia visava estabelecer responsabilidades mútuas entre professores e estudantes, sendo amplamente difundida no intuito de suprir a falta de professores (BASTOS e FARIA 1999; MANACORDA 1989). A partir disso, segundo Bastos (1999) no século XIX o ensino mútuo expandiu-se para países de colonização espanhola e foi muito utilizado porque, não podendo contar com mestres capacitados, utilizava-se dos melhores alunos - monitores - para transmitir aos demais aprendizes o conhecimento que havia sido assimilado junto ao professor.
No Brasil, a origem da monitoria remonta ao período colonial a partir de iniciativas de Universidades por meio da implantação e regulamentação da Lei 5.540, de 28 de novembro de 1968, a qual determinou "normas de organização e funcionamento para o ensino superior" (DIAS 2007). Fundamentadas nesta lei, as atividades de monitoria foram introduzidas com mais vigor no universo acadêmico brasileiro a partir do Artigo 41, o qual determinou:

"As universidades deverão criar as funções de monitor para estudantes do curso de graduação que se submeterem a provas específicas, nas quais demonstrem capacidade de desempenho em atividades técnico-didáticas de determinada disciplina (BRASIL, 1996).”

Nesse sentido, a monitoria é considerada um serviço de apoio pedagógico, oferecido aos discentes interessados em aprofundar conteúdos vistos em sala de aula, com a finalidade de esclarecer dúvidas oriundas dos estudos individuais ou em grupo (HAAG et al. 2008).

A tutoria, apesar de possuir diferença mínima da monitoria, emerge como outra espécie de fomento ao ensino, visando auxiliar aos alunos no campo educacional. Esta modalidade remonta à mitologia greco-latina onde o tutor era definido como alguém destinado à proteção divina, enquanto na educação romana, a prática da tutoria associava-se ao processo de helenização decorrente da conquista da Grécia pelos romanos. Enquanto isso os gregos detinham notório saber e eram transformados em pedagogos para educar as crianças da nobreza romana (MIRANDA 2009). No final da Idade Média aparecem os tutores da educação individual, com caráter humanista, promovida pelos mestres livres - ensino particular (GILES 1987). 
Ao adentrar no período renascentista, observase que tutores e preceptores orientavam os alunos de forma individualizada e específica, tornando a educação mais personalizada. Atualmente a tutoria segue essa mesma linha de pensamento, orientando estudantes ou pessoas da comunidade, individualmente ou em grupo por meio dos próprios estudantes universitários ou professores (FRISON 2012; BRUTTEN 2008).

No sentido de apoiar os discentes nas questões acadêmicas, as ações da Assistência Estudantil (AssEs), criadas pelas Instituições de Ensino Superior (IES) desde os anos de 1930, baseavam-se em programas de alimentação e moradia universitária. Tais medidas se tornaram amplas em todos os níveis de ensino na década de 40 quando a Constituição de 1946 expressava através do art. 172 que "Todo sistema de ensino deveria obrigatoriamente possuir serviços de assistência educacional que assegurassem aos alunos necessitados condições de eficiência escolar (MIRANDA 2009)." A partir disso, todas as IES foram obrigadas a implementar estratégias para auxiliar discentes nas dificuldades financeiras e no desempenho acadêmico.

Seguindo essa perspectiva de suporte educacional ao discente, a AssEs da Universidade Estadual do Sudoeste da Bahia (UESB) aderiu ao programa de tutoria, no qual as aulas são ofertadas apenas para as disciplinas com alto índice de reprovação (acima de 40\%) segundo levantamento apresentado pela Pró-Reitoria de Graduação (PROGRAD), referentes aos períodos letivos de 2011.1 a 2016.2 (BRASIL 2018a).

A partir da premissa da importância da aplicação da metodologia de tutoria e de monitoria em disciplinas de complexa compreensão como a Biofísica, é necessário analisar a eficiência do desenvolvimento desses métodos, o seu alcance e os resultados atingidos junto aos discentes. Para tanto, este estudo busca descrever e discutir a percepção de discentes da UESB a respeito da monitoria e tutoria da disciplina Biofísica.

\section{MATERIAIS E MÉTODOS}

Trata-se de uma pesquisa aplicada, exploratória, de levantamento quali-quantitativa, realizada durante a vigência do Programa de Monitoria da UESB nos anos de 2018 e 2019 (BRASIL 2018b), paralelo à tutoria do Programa de Assistência Estudantil (PRAE) (BRASIL 2018a), ambos atendendo à disciplina Biofísica. Participaram do estudo 81 monitorandos do terceiro semestre do curso de Fisioterapia e 6 tutorandos, sendo 5 destes do curso de Farmácia e 1 do curso de Fisioterapia. Os participantes da pesquisa são compostos por estudantes da disciplina Biofísica do período letivo 2018.1, 2018.2 e 2019.1, na UESB campus Jequié.

Ao final dos períodos supracitados um questionário eletrônico, que já compõe a avaliação didática da disciplina, foi enviado através da plataforma Google Forms aos e-mails dos discentes. O formulário continha 15 questões objetivas dentres às quais destacam-se: Qual a sua situação no curso? Com que frequência você buscou pelo auxílio da monitoria ao longo do semestre? Com que frequência você buscou pelo auxílio da tutoria durante o semestre? No decorrer da monitoria, as dúvidas foram esclarecidas, pouco esclarecidas ou não foram esclarecidas?

Os dados foram organizados automaticamente em planilhas no Software Excel (SoEx), através de gráficos de setor e coluna com a porcentagem e número absoluto das respostas de cada variável pesquisada. A coleta e exploração dos dados foram feitas através do SoEx por permitir realizar análise descritiva, caracterizando a 
população do estudo, estimando as frequências das variáveis e suas respectivas proporções. Ressalta-se que não houve identificação de nenhum participante, a fim de garantir o anonimato dos mesmos.

\section{Descrição da Disciplina}

A disciplina Biofísica é ofertada semestralmente pelo Departamento de Ciências Biológicas (DCB) aos cursos de Ciências Biológicas (Licenciatura e Bacharelado), Enfermagem, Farmácia e Fisioterapia. Possui 2 créditos teóricos e 1 prático (com exceção do curso de Farmácia, 2 créditos teóricos apenas). Sua distribuição se baseia em métodos teóricoprático, fazendo uso de diversos recursos didáticos.

O programa da disciplina não varia entre os cursos, com exceção do curso de Farmácia. Baseado nos ramos da Biofísica proposto por Popescu (1994) buscou-se esclarecer neste estudo apenas a ementa dos cursos de Fisioterapia e Farmácia. A primeira área discute temas de biofísica da água, das membranas, dos sistemas (cardiovascular, neuromuscular, nervoso e respiratório), biofísica da visão, processos físicoquímicos, física das radiações, radiobiologia e radioproteção, além de abordar os agentes físicos sobre os organismos. Já o programa de Farmácia enfatiza os pilares específicos para o exercício desta profissão, a saber: medidas em ciências biomédicas; água, soluções e suas propriedades físicas; $\mathrm{pH}$ e tampões; marcação radioisotópica, autorradiografia, microscopia óptica e eletrônica, eletroforese, cromatografia, biofísica de membranas (filtração, diálise e transporte), métodos hidrodinâmicos e bioeletrogênese.

As aulas teóricas da disciplina são ministradas nas salas de aula do campus de Jequié. As salas são amplas, climatizadas e equipadas com projetor. A instituição possui setor de audiovisual responsável pela assistência aos discentes e docentes através de outros equipamentos para melhor desenvolver as aulas teóricas. Já as aulas práticas são desenvolvidas no Laboratório de Fisiologia e Biofísica, localizado no módulo de laboratórios Edson Cardoso dos Reis, e apresenta espaço físico adequado à quantidade de alunos, além de ser equipado para dar suporte às atividades ali desenvolvidas, com bancadas para experimentos, quadro branco e equipamentos diversos para uso no laboratório.

As avaliações da disciplina foram realizadas a partir de alguns instrumentos, a saber: estudos de artigo, estudos dirigidos, discussões, provas teóricas, seminários e relatórios de aulas práticas realizadas durante o semestre. É selecionado semestramente um monitor, através de seleção com prova teórica e entrevista, com o objetivo de melhor desenvolver a disciplina e potencializar o intelecto dos alunos.

Ao final de cada semestre é realizada uma avaliação informal (questionário estruturado dirigido e sem identificação) com os discentes de cada turma a fim de obter um feedback do trabalho desenvolvido, possibilitando melhorias na metodologia utilizada. O questionário é enviado ao $e$-mail de cada discente por meio do Software do Google Forms (SGF), o qual é possível ser respondido a qualquer momento através de celular Android, iPhones, Tablet, Notebook, desde que conectados à uma conta Google. O SGF permite a cada discente responder ao questionário apenas uma vez, a partir do aceite de participação. As respostas são arquivadas automaticamente em arquivo Excel pelo próprio $S G F$ sem qualquer identificação dos discentes.

\section{Metodologia utilizada nos auxílios}

Nas aulas de monitoria foi utilizado como modelo pedagógico a técnica de Brainstorming para discussão dos assuntos. Neste recurso sucede-se a 
"tempestade de ideias" na qual os participantes escolhem um conteúdo e apresentam tudo o que sabem sobre o assunto até esgotar as informações, sem fazer qualquer pré-julgamento. Após isso, realiza-se momentos de reflexão sem censura para não prejudicar o processo. Em seguida, é feita uma análise com a participação de todos, motivando a organização das ideias (LOPES e PONTES 2000).

De acordo com Osborn (1957) a técnica Brainstorming consiste em uma dinâmica de grupo em que se busca soluções para problemas, ideias inovadoras e agregação de conhecimentos, por meio de reuniões mediadas por um líder responsável por encorajar os participantes a expressarem-se. Este líder pode ser um professor ou qualquer indívíduo que esteja apto á organização de informações, baseadas em teorias bem fundamentadas.

Segundo Chammas et al., (2017) para este método funcionar corretamente deve-se estabelecer as seguintes regras: julgamento de valor são descartados e as críticas e ideias devem ser guardadas para logo depois; espontaneidade é sempre permitida e quanto mais lúcida a ideia, melhor; quantidade é desejada, pois quanto maior o número de ideias, maior a variabilidade para discussão; e por último, combinação e aperfeiçoamento são procurados, na qual todos podem sugerir formas para as concepções de outros participantes serem transformadas em ideias melhores por meio da união das falas expressas.

Seguindo essa perspectiva, o monitor solicita aos alunos a expressarem suas compreensões sobre as propriedades biofísicas da água e os mesmos vão dizendo sem necessariamente uma ordem ou lógica das ideias neste primeiro momento, por exemplo: DISCENTE A - "a água é o principal solvente do planeta”; DISCENTE B - "é constituida pela molécula de $\mathrm{H}_{2} \mathrm{O}$ ”; DISCENTE A novamente - "é encontrada na natureza em três fases: sólida, líquida e gasosa", DISCENTE C - "tem o poder de retirar impurezas da maioria dos materiais"; DISCENTE D - "é a principal responsável pela manutenção da vida na terra".

Observa-se no exemplo anterior que há espaço de falas e alternância entre os participantes de acordo a vontade e necessidade de cada um. Concluindo esta primeira etapa, o monitor retorna aos tópicos falados, ratificando, retificando ou complementando as ideias. Como exemplo, o monitor, apoiado no autor Heneine (2006), complementa a primeira fala do discente B: “... além disso, a molécula de água possui três atómos que se ligam covalentemente, apresentando angulação de $105^{\circ}$, favorecida pela diferença de cargas entre a região do oxigênio e dos hidrogênios".

Nesta técnica, além das ações supramencionadas, é realizado uma ponte entre as informações com o intuito de trazer à tona elementos importantes para a discussão que talvez os participantes tenham esquecidos de mencionar, por exemplo: fala do monitor baseada em estudos na bibliografia Heneine (2006) - “importante destacar que a água é caracterizada como solvente universal por participar de várias soluções, inclusive de possuir propriedade anfipática, responsável por retirar impurezas devido a sua polaridade, favorecendo a sua ligação com estruturas de polaridades tanto negativas como positivas, ou as duas concomitantemente."

De acordo com Frison (2016) a técnica Brainstorming é uma estratégia metodológica eficaz no ambiente universitário, pois além de criar um clima descontraído, importante para reduzir as tensões geradas no processo ensino-aprendizagem, possibilita aos alunos o resgate das experiências e vivências que "darão vida e significado" ao conteúdo a ser estudado. Além disso, esta ação corrobora com uma das competências atribuídas ao monitor na resolução 
UESB nº 60 de 2010, Cap IV, art. $8^{\circ}$, alínea III, a saber: "facilitar o relacionamento entre discente(s) e docente(s) na execução e melhoria do processo ensino/aprendizagem" (UESB, 2010, p. 3).

\section{Atividades realizadas na monitoria}

De acordo a resolução $n^{\circ}$ 60/2010 da UESB cabe ao monitor da disciplina dispor de 12 horas semanais para a realização de atividades, constituídas por reunião com professor orientador, planejamento e avaliação das aulas; leitura e análise das atividades produzidas pelos alunos, elaboração e correção de estudo dirigido; acompanhamento das aulas, orientação aos discentes e intervenção em aula prática (BRASIL 2010).

Para cumprir a carga horária, as atividades podem ser realizadas durante as aulas práticas e teóricas, juntamente com a docente, assim como em horários diferentes das aulas. Dentre a gama de ações realizadas pelo monitor destaca-se a aplicação de um estudo dirigido (ED) por unidade, utilizando livros impressos de Biofísica obtidos na Biblioteca Jorge Amado (BJA) da UESB e artigos científicos extraídos das bases de dados: Literatura Latino-Americana e do Caribe em Ciências da Saúde (LILACS), Medical Literature and Retrieval System Online (Medline) e Scientific Electronic Library Online (SciElO).

Em consequência da dinâmica da monitoria ter por objetivo despertar no discente o interesse pela carreira acadêmica (Cap III, art. $7^{\circ}$, alínea III da resolução $\mathrm{n}^{\circ} 60$ de 2010) a professora orientadora solicita ao monitor intervenção nas aulas teóricas e/ou práticas, elaboração de ED e assistência nas correções das atividades. Tais ações permitem maior troca de aprendizado, tanto para o monitor como para os alunos, além de fortalecer e estreitar o vínculo social acadêmico.

\section{Atividades realizadas na tutoria}

$\mathrm{Na}$ tutoria, os discentes interessados se dirigiam por livre vontade ao setor do PRAE da universidade os quais preenchiam uma ficha com o nome completo, telefone, curso, disciplina solicitada, dias e horários disponíveis. Em seguida, a coordenadora do programa entrava em contato com o tutor e passava os dados das solicitações dos alunos. O tutor, por sua vez, se comunicava com o discente e combinava o melhor dia, horário e local para realizar os encontros de tutoria, assim como os conteúdos de interesse. Ressalta-se que o espaço escolhido pelos alunos foi a BJA em horários diversos.

As questões para discussão nas tutorias eram elaboradas pelo tutor, baseadas em livros de Biofísica da BJA e artigos científicos da LILACS, Medline e SciElO. Além disso, o modelo de questões dos EDs eram personalizadas respeitando o perfil de cada discente, considerando a escolha de cada um. Alguns solicitavam questões abertas p. Ex.: discorra sobre o processo de despolarização do miocárdio; ou fechadas, p. Ex: quais íons são responsáveis pela hiperpolarização da membrana biológica? A) $\mathrm{Na}^{+}$B) $\mathrm{Na}^{+}$e $\mathrm{K}^{+}, \mathrm{C}$ ) Apenas $\mathrm{K}^{+} \mathrm{D}$ ) $\mathrm{Cl}^{-}$, E) $\mathrm{Cl}^{-}$e $\mathrm{K}^{+}$), enquanto outros preferiam perguntas mistas.

As tutorias eram realizadas com um discente por vez, tendo em vista que é permitido auxiliar no máximo três alunos por atendimento de acordo com as normas estabelecidas pelo programa de tutoria do PRAE. Esta estratégia foi utilizada pelo projeto para evitar a dispersão da atenção e raciocínio dos alunos, potencializar o aproveitamento e rendimento dos mesmos e prover a máxima atenção dada a eles, favorecendo a assimilação dos conteúdos estudados.

\section{RESULTADOS E DISCUSSÃO}


Foram consideradas na análise as participações obtidas no período de quinze dias, contados após a última aula do semestre nos períodos 2018.1, 2018.2 e 2019.1. Participaram deste estudo 81 alunos monitorandos, sendo 45 do curso de Fisioterapia e 36 do curso de Farmácia. Houve predomínio do sexo feminino $(79,01 \%)$ no total da amostra, assim como em todos os períodos e cursos, corroborando com os estudos de Andrade et al., (2018) e Figueiredo et al.,
(2016), evidenciando a presença e participação das mulheres nas monitorias da disciplina ora analisada.

A idade variou de 18 a 46 anos, havendo prevalência da faixa etária de 18 a 21 anos $(70,37 \%)$. A faixa etária menos predominante foi de 39 a 46 anos, exibindo o percentual de $2,47 \%$. Em relação a situação no curso $83,96 \%$ dos pesquisados não estavam, até o momento da pesquisa, com pendência em nenhuma disciplina da grade curricular do curso. As demais informações podem ser visualizadas na tabela 1 .

Tabela 1. Características dos monitorandos segundo sexo, faixa etária e situação no curso.

\begin{tabular}{l|cc}
\hline SEXO & $\mathbf{n}$ & $\%$ \\
Masculino & 16 & 19,75 \\
Feminino & 64 & 79,01 \\
Não informado & 01 & 1,24 \\
FAIXA ETÁRIA & & \\
18 a 21 anos & 57 & 70,37 \\
22 a 26 anos & 22 & 27,16 \\
39 a 46 anos & 02 & 2,47 \\
SITUAÇÃO NO CURSO & & \\
Regular no curso & 68 & 83,96 \\
Irregular no curso & 12 & 14,80 \\
Não informado & 01 & 1,24 \\
Fonte: Arquivos da docente. & &
\end{tabular}

Na tabela 2 observa-se que 58,02\% dos discentes buscaram pela monitoria de 1 a 2 vezes durante o semestre e $27,16 \%$ procuraram o auxílio em uma frequência de 3 a 4 vezes. No entanto, considerável proporção de estudantes 12,34\% não buscou a monitoria para a retirada de dúvidas. Sobre o motivo pelo qual não buscaram ajuda do monitor, houve unanimidade na resposta falta de tempo, corroborando com os estudos de Botelho et al., (2019). Além desta justificativa, os discentes apontaram haver incompatibilidade de horário com o monitor e por este motivo não acharam necessário a busca.

Tabela 2. Busca da monitoria durante o semestre letivo.

\begin{tabular}{lcc}
\hline FREQUENCIA & n & \% \\
1 a 2 vezes & 47 & 58,02 \\
3 a 4 vezes & 22 & 27,16 \\
5 a 6 vezes & 01 & 1,24 \\
7 a 8 vezes & 01 & 1,24 \\
Não buscou monitoria & 10 & 12,34 \\
TOTAL & 81 & 100 \\
\hline
\end{tabular}

Fonte: Arquivos da docente. 
A condição das dúvidas após as aulas de monitorias está ilustrada no Gráfico 1, destacando cerca de $80 \%$ dos alunos de Fisioterapia que tiveram suas dúvidas esclarecidas durante os atendimentos de monitoria e aproximadamente $70 \%$ dos alunos de Farmácia nesse mesmo estado.

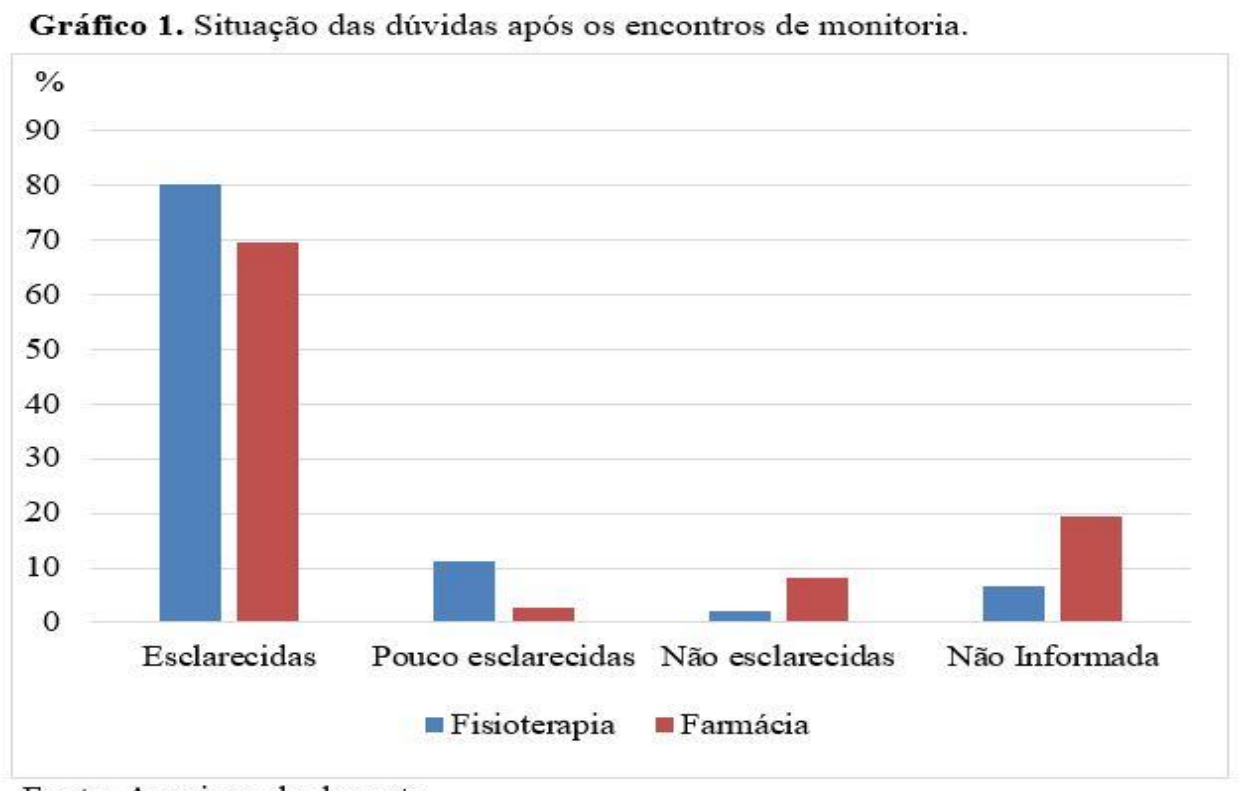

Fonte: Arquivos da docente.

A qualidade do método aplicado na orientação das monitorias para $43,2 \%$ dos alunos foi boa, embora $3,7 \%$ não qualificaram como um bom método (tabela 3). No entanto, $12,35 \%$ dos discentes não se posicionaram sobre a questão, por não terem buscado o auxílio, logo, desconheciam o processo metodológico utilizado.

Tabela 3. Método utilizado para orientação nas monitorias.

\begin{tabular}{lcc} 
& $\mathbf{n}$ & $\%$ \\
Ótimo & 19 & 23,47 \\
Bom & 35 & 43,2 \\
Razoável & 14 & 17,28 \\
Ruim & 03 & 3,7 \\
Não informado & 10 & 12,35 \\
TOTAL & 81 & 100 \\
\hline
\end{tabular}

Fonte: Aquivos da docente.

Adentrando na outra modalidade de auxílio aos discentes, ofertada pelo Programa de Desempenho Acadêmico (PRAE) observa-se na tabela 4 que a predominância de participantes foi também do sexo feminino $(83,33 \%)$ e a idade da amostra oscilou de 20 a 46 anos de idade, com a mesma predominância de idade dos participantes da monitoria, 20 anos. Da amostra de 6 alunos tutorandos, mais da metade (83,33\%) dos auxiliados cursavam Farmácia enquanto um indivíduo cursava Fisioterapia. Acerca da situação no curso, metade estavam regulares com as disciplinas da grade curricular de seu curso. 
Tabela 4. Características dos tutorandos segundo sexo, idade, curso e situação no curso.

\begin{tabular}{lcc}
\hline SEXO & n & \% \\
Masculino & & \\
Feminino & - & - \\
Não informado & 5 & 83,33 \\
IDADE & 1 & 16,67 \\
20 anos & & \\
21 anos & 3 & 50 \\
23 anos & 1 & 16,6 \\
46 anos & 1 & 16,6 \\
CURSO & 1 & 16,6 \\
Farmácia & & \\
Fisioterapia & 5 & 83,33 \\
SITUAÇÃO NO CURSO & 1 & 16,67 \\
Regular no curso & & \\
Irregular no curso & 3 & 50 \\
Não informado & 3 & 50 \\
\hline Fonte: Arquivos da docente. & - & - \\
\hline
\end{tabular}

Ao serem indagados sobre a frequência na tutoria durante o semestre, a maioria $(66,67 \%)$ dos respondentes revelaram procurar este método de 3 a 4 vezes como mostra a tabela 5 . No entanto, não foi identificado busca do método acima de 5 vezes.

Tabela 5. Frequência de busca da tutoria durante o semestre letivo.

\begin{tabular}{lcc}
\hline FREQUÊNCIA & n & $\%$ \\
1 a 2 vezes & & \\
3 a 4 vezes & 2 & 33,33 \\
5 a 6 vezes & 4 & 66,67 \\
7 a 8 vezes & - & - \\
9 a 10 vezes & - & - \\
Acima de 10 vezes & - & - \\
TOTAL & - & - \\
\hline
\end{tabular}

Fonte: Arquivos da docente.

Dos discentes que buscaram as tutorias, $66,66 \%(4 / 6)$ revelaram que as dúvidas relacionadas aos conteúdos foram esclarecidas durante os atendimentos e 33,34\% (2/6) evidenciaram pouco esclarecimento das dúvidas. Além disso, investigou-se sobre o método utilizado nas tutorias para orientar/esclarecer, obtendo $50 \%$ das respostas na categoria ótimo, $25 \%$ marcaram bom e os outros $25 \%$ classificaram como método razoável.

Os auxílios de ensino explorados neste estudo busca trazer para a realidade do alunado a proximidade entre imaginação e conteúdos, com intuito de facilitar a identificação e aprendizagem das Ciências Físicas e Biológicas. Dessa forma, os resultados obtidos permitem inferir que as ferramentas de apoio pedagógico, monitoria e tutoria, foram eficazes no entendimento de assuntos que se mostraram obscuros para os acadêmicos.

A técnica Brainstorming foi propositalmente aplicada neste cenário metodológico resultando na efeverscência de ideias, conceitos, dúvidas que produziram o pensamento crítico e o surgimento de 
novas ideias, estimulando $\mathrm{o}$ debate entre $\mathrm{o}$ monitor/discente.

Andrade et al., (2018) salienta que o monitor, naquele assunto que ele domina um pouco mais, consegue partilhar e ajudar os monitorandos que estão estudando o assunto pela primeira vez. Além desse viés, através do processo contínuo e dinâmico da modalidade em questão, existe a troca de experiência entre o aluno monitor e o aluno assistido, favorecendo transformações sociais e intelectuais das duas esferas.

$\mathrm{O}$ discente não monitor apoia-se no monitor onde encontra espaço fértil ao esclarecimento de dúvidas e melhoramento de habilidades, facilitando o aprendizado por meio da redução da distância alunomonitor e aluno não monitor, assim como pela transmissão do conhecimento com a linguagem mais acessível. Nesta linha de pensamento, Feizabadi (2009) esclarece que essa acessibilidade está presente na manutenção de contato, linguagem mais adaptada e próxima da realidade do estudante, diferindo da relação aluno-professor que muitas vezes é representada por timidez e receio por parte do aprendiz.

Apesar da execução dos programas de auxílio pedagógico aos universitários se mostrar eficaz e de grande relevância, existem barreiras operacionais que dificultam o andamento do processo de construção do conhecimento, como a falta de tempo dos discentes. Este estudo revela que dez alunos não procuraram monitoria, no entanto, houve a frequência de busca de 1 a 8 vezes pelos alunos que possivelmente colocaram a revisão de conteúdos como prioridade. A justificativa para a baixa procura pela monitoria neste estudo é corroborada com os esudos de Galdino e Abrantes (2019) e Figueiredo et al., (2016) os quais apontaram para a indisponibilidade de tempo dos alunos em participar das atividades propostas pelo monitor, baseadas na disputa de tempo entre mercado de trabalho e atividades acadêmicas.

No entanto, o resultado do estudo de Barroso e Gomes (2016) revela que os horários da monitoria não eram compatíveis com os dos discentes pesquisados em seu estudo, visto haver atraso na grade curricular comprometendo, dessa forma, a adesão à monitorias por motivo de choque de horários entre a monitoria e outras disciplinas. No estudo de Barroso e Gomes outras justificativas foram expostas para a não procura das monitorias, destacando a preferência em estudar sozinho(a), tirar dúvidas em sala de aula e distância entre o domicílio do aluno e a universidade.

Ainda neste sentido, uma pesquisa realizada na Universidade do Estado do Rio de Janeiro mostra que a principal dificuldade encontrada na efetivação das monitorias era a procura irregular dos discentes pelos atendimentos do monitor (AMANTO, 2016). Em contrapartida com o estudo de Amanto, uma pesquisa de avaliação do programa de monitoria realizada na Universidade Federal Fluminense (UFF) revelou um alto índice (19/23) de assiduidade dos participantes nos encontros de monitoria (BRASIL 2013). Apesar dessa tenacidade, os discentes da UFF pontuaram dificuldades logísticas para o deslocamento até o local das monitorias, como atrasos em transporte público ou distância excessiva entre o local da monitoria e a residência do aluno.

$\mathrm{Na}$ outra modalidade de auxílio, a tutoria, verifica-se que a maior parte dos tutorandos $(66,67 \%)$ buscou mais vezes o método (3 a 4 vezes), visto que este oferta uma atenção focada na individualidade de cada discente, fato que é difícil ocorrer nas monitorias, porque o tempo de permanência nestas é mais reduzido e o número de estudantes por encontro é maior. Associando estas dificuldades da monitoria com a proposta da tutoria, depreende-se haver melhor 
aproveitamento do tempo dos discentes quando há um número reduzido de alunos nos encontros e a atenção é voltada individualmente para retirada das dúvidas.

A amostra obtida das duas modalidades de ensino foi abrangente em seus respectivos cursos e períodos, apesar da grande dispersão dos estudantes, visto que o período escolhido para o envio do questionário coincidiu com o início das férias discente. Não obstante a essa barreira, os resultados mostraram que ambas as modalidades denotam eficácia no que tange ao esclarecimento das dúvidas e fortalecimento da aprendizagem, apesar de alguns discentes não terem tempo livre para se dedicarem aos auxílios e outros não precisar buscar os métodos ofertados.

O estudo de Frison e Moraes (2011) evidencia a importância de conhecer os motivos pelos quais os discentes procuram ou não os auxílios disponíveis, para criação de políticas que reduzem essa barreira. Além disso, Frison e Moraes elencam algumas variabilidades encontradas no cotidiano dos discentes, potencialmente influenciadoras na participação acadêmica dos discentes: localização geográfica da universidade, o tipo de curso, o perfil da turma e do aluno, a demanda de atividades e as prioridades no agendamento de horário.

Por isso, este estudo contribui para a redução de estigmas sobre as modalidades de auxílio aos discentes a partir do momento em que passa a conhecer o perfil dos estudantes e as características envolvidas. Apesar dos empecilhos na procura e participação dos métodos de apoio ao ensinoaprendizagem revelados neste estudo, foi coletivo entre os períodos e modalidades o reconhecimento dos educandos sobre a importância da técnica de auxílio à aprendizagem e a relevância do monitor/tutor no apoio às disciplinas acadêmicas.
Além disso, o método utilizado nos auxílios discutido neste estudo possibilita confluir debates sobre os diversos conteúdos educacionais assim como encorajar a participação ativa dos alunos envolvidos no processo. Neste nível de raciocínio, um estudo realizado em uma universidade de Bucaramanga na Colômbia revela que os acadêmicos participantes dos auxílios de ensino e aprendizagem aprendem a construir e reconstruir conhecimento através de partilha de ideias críticas e reflexivas, mediadas por um estudante de semestre mais avançado (CardosoOrtiz, 2011). O estudo de Martin (2016) destaca que os alunos pesquisados por ele atribuíram benefícios pedagógicos aos métodos de monitoria e tutoria, como: melhora do pensamento crítico, autonomia do aprendizado, motivação, habilidades colaborativas e comunicativas.

Por fim, o presente estudo apresentou como dificuldades o baixo número de discentes matriculados na disciplina Biofísica, por período e curso, refletindo no tamanho da amostra. Além disso, há poucos estudos na literatura científica sobre o método de tutoria acadêmica, visto ser recentemente empregado pelas universidades. Este fato é comprometedor, mas não impeditivo no processo discursivo desta pesquisa.

\section{CONCLUSÃO}

A partir das análises percebe-se que os monitorandos reconhecem a importância de um monitor de disciplina para ampliar o processo de aprendizagem, apesar de haver falta de tempo, considerando o excesso de atividades acadêmicas extracurriculares que os discentes precisam cumprir. 
Além disso, a monitoria se apresentou efetiva aos pesquisados, no sentido do esclarecimento das dúvidas extraclasse e revelou-se um bom método para sanar as dúvidas dos conteúdos.

Os discentes assistidos pelo PRAE revelaram que o método utilizado para orientação nas tutorias não deixou lacunas no conhecimento, reforçando que as dúvidas foram elucidadas nos atendimentos. Tais resultados permitem inferir que o aprendizado não fluiria com o mesmo êxito sem a utilização desses métodos. Algumas adequações futuras podem ser propostas para abranger maior quantidade de alunos, tanto na perspectiva metodológica quanto na gestão de horários, sem desviar da essência do método.

Assim, nota-se a importância de entender as necessidades dos alunos para reavaliar as formas de abordagem nos encontros de monitoria/tutoria a fim

\section{REFERÊNCIAS}

AMANTO. D. T. Programa de Monitoria no Ensino Superior: O Estudo de Caso no CEFET/RJ. 2016. f.110. Dissertação (Mestrado em Sistemas de Gestão) - Universidade Federal Fluminense, Rio de Janeiro, 2016. Disponível em:< https://app.uff.br/riuff/handle/1/4302>.

ANDRADE， E.G.R.; RODRIGUES， I.L.A.; NOGUEIRA, L.M.V.; SOUZA, D.F. Contribution of academic tutoring for the teaching-learning processin nursing undergraduate studies. Rev Bras Enferm. 2018. Disponível em: <https://doi.org/10.1590/0034-7167-2017-0736>.

BARROSO, I., GOMES, C.H. A importância das monitorias no ensino superior e seu papel na diminuição da evasão. Anais: VII Salão Internacional de Ensino, Pesquisa e Extensão Universidade Federal do Pampa, 2016. Disponível em:

<http://200.132.146.161/index.php/siepe/article/vie wFile/19329/7622>. de avançar na ampliação do conhecimento a partir de um estudo orientado e garantir melhora no desempenho acadêmico.

Salienta-se ainda que a presença da defasagem de aprendizagem advinda da educação básica dificulta todo o percurso do aprendizado no ensino superior, sendo um dos fatores responsáveis pela evasão do aluno da disciplina, do curso ou até mesmo da instituição de ensino.

\section{AGRADECIMENTO}

Agradecemos à acadêmica Alessandra dos Santos de Santana pelas contribuições no desenvolvimento desse trabalho.

Todos os autores declararam não haver qualquer potencial conflito de interesses referente a este artigo.

BASTOS, M.H.C.; FARIA, F.L.M. A escola elementar no século XIX: o método monitorial/mútuo. Passo Fundo: EDIUPF, 1999.

BASTOS, M.H.C. O ensino mútuo no Brasil (1808 - 1827). In M.H.C. Bastos \& L.M. de Faria Filho (Orgs.), A escola elementar no século XIX ( $p$. 95 - 118). Passo fundo: Ed. UPF. 1999.

BOTELHO, L. V.; LOURENÇO, A. E. P.; LACERDA, M. G. DE; WOLLZ, L. E. B. Academic monitorship and professional training in health: an integrative review. ABCS Health Sciences, v. 44, n. 1, 30 Apr. 2019.

BRASIL. Universidade Estadual do Sudoeste da Bahia. Edital $n^{\circ} 01$ de 2018. Vitória da Conquista, 28 de jun., 2018b. Disponível em: <http://www2.uesb.br/wpcontent/uploads/2018/07/01-edital-de-Monitoria2018.1-.pdf>.

Universidade Estadual do Sudoeste da Bahia. Edital no 058 de 2018. Vitória da Conquista, 
26 de mar. 2018a. Disponível em: <http://www.uesb.br/editais/2018/03/edital_05818.pdf>.

Universidade Estadual do Sudoeste da Bahia. Resolução $n^{\circ}$ 60, de 18 de agosto de 2010. Vitória da Conquista, BA, p. 3, de ago. 2010. Disponível em: <http://www2.uesb.br/transparencia/uploads/conse pe/Resolu\%C3\%A7\%C3\%A3o\%2060-2010\%20$\% 20$ Programa\%20de\%20Bolsa\%20de\%20Monitor ia\%20(Revoga\%2004-2001).pdf >.

Universidade Federal Fluminense. Pesquisa de avaliação do programa de monitoria da UFF, 2013. Disponível em: <http://www.noticias.uff.br/noticias/2014/10/pesqu isa-de-avalicao-do-programa-de-monitoriadigital.pdf >

\section{Diretrizes e Bases da Educação}

Nacional. Lei n 9.394 de 20 de dezembro de 1996. Disponível em: <http://www.planalto.gov.br/ccivil_03/leis/19394.h tm>.

BRUTTEN, E. (2008). A tutoria na educação: Suas origens e concepções. In Atas do XVI Colóquio AFIRSE/AIPELF — "Tutoria e mediação em educação: Novos desafios à investigação educacional". Lisboa: Universidade de Lisboa.

CARDOSO-ORTIZ, C.E. Tutoria entre pares como una estratégia pedagógica universitaria. Educ.Educ. Vol. 14, n.2. 2011. ISSN: 0123-1294

CHAMMAS, A; QUARESMA, M; MONT'ALVÃO, C; "A dicotomia entre teoria e prática do brainstorming", p. 2320-2329. In: São Paulo: Blucher, 2017. Disponível em: $<$ https://www.proceedings.blucher.com.br/articledetails/a-dicotomia-entre-teoria-e-prtica-dobrainstorming-25901>.

CHAGAS FILHO, Carlos. Comentários sobre a biofísica. In: Medicina, Cirurgia e Farmácia. Rio de Janeiro, n. ${ }^{\circ}$ 93, vol. 4, 1943.

DANTAS, O.M. Monitoria: fonte de saberes à docência superior. Rev. Bras. Estud. Pedagog., Brasília, v. 95, n. 241, p. 567-589, Dec. 2014. Disponível em: $<$ http://www.scielo.br/scielo.php?script=sci_arttext \&pid=S2176-
$66812014000300007 \& \operatorname{lng}=\mathrm{en} \& \mathrm{nrm}=\mathrm{iso}>$. Acesso em 02 nov. 2018.

DIAS, A.M.I. A monitoria como elemento de iniciação à docência: ideias para uma reflexão. In: SANTOS, Mirza Medeiros dos; LINS, Nostradamus de Medeiros Lins (Org.). A monitoria como espaço de iniciação à docência: possibilidades e trajetórias. Natal, RN: EDUFRN: Editora da UFRN, 2007. (Coleção Pedagógica; n. 9)

FEIZABADI, M. S. An experience teaching na undergraduate level course in Biophysics. v. 48, 35 (1), May 2009. Disponível em: < https://files.eric.ed.gov/fulltext/EJ858950.pdf>.

FIGUEIREDO, T.C.; FILIPPIN, N. T.; VENDRUSCULO, A.P. Perception of physical therapy students about academic monitoring. Fisioter Bras 17(5): 450 - 456, 2016. Disponível em:

http://docs.bvsalud.org/biblioref/2018/04/882992/p ercepcao-dos-discentes-de-fisioterapia-acerca-damonitoria-academica.pdf>.

FRISON, L.M.B. Tutoria entre estudantes: uma proposta de trabalho que prioriza a aprendizagem. Revista Portuguesa de Educação, Braga, v. 25, n. 1, p. 217-240, 2012. Disponível em: < https://revistas.rcaap.pt/rpe/article/view/3008>.

Monitoria: uma modalidade de ensino que potencializa a aprendizagem colaborativa e autorregulada. Pro-Prosições, v. 17, n. 1, 2016. Disponível em:

http://www.scielo.br/scielo.php?pid=S0103-

$73072016000100133 \&$ script $=$ sci_abstract $\&$ tlng $=p t$ $>$.

FRISON, L.M.B.; MORAES M.A.C. As práticas de monitoria como possibilitadoras dos processos de autorregulação das aprendizagens discentes. Poieis pedagógica, v. 8 , n. 2, p. 144-158, abr. 2011. ISSN 2178-4442. Disponível em: $<$ https://www.revistas.ufg.br/poiesis/article/view/1 4064>.

GALDINO, E.T.S.; ABRANTES, K.N.F.C. Desafios da monitoria acadêmica: percepção dos alunos monitores e monitorados. Enc. de extensão, docência e iniciação científica. ISSN 2446-6042

GILES, T.R. História da Educação. São Paulo: EPU, 1987

GUIMARÃES, F. S. P. Biofísica: Elaboração de um material didático para o Curso de Enfermagem. 
Tese, Belo Horizonte - MG, 2010. Disponível em: $<$

http://www.biblioteca.pucminas.br/teses/EnCiMat_ GuimaraesFS_1.pdf>.

HAAG, G.S.; KILLING, V.; SILVA, E.; MELO, S.C.B.; PINHEIRO M. Contribuições da monitoria no processo ensino aprendizagem em enfermagem. Rev. Bras. Enferm. 2008; 61:215-20. Disponível em:

http://www.scielo.br/pdf/reben/v61n2/a11v61n2.pd $\mathrm{f}>$.

HENEINE, I.F.. Biofísica Básica. editora atheneu, sp, 2006.

JÚNIOR, J.; BOAS, J.; SOUZA, N. Monitoria nas Ciências Exatas: uma aprendizagem colaborativa. Seminário de Projetos de Ensino (ISSN: 2674-8134), v. 3, n. 1, 1 ago. 2019.

LEAL, M. R. C. Aprendizagem em ciências biológicas na visão de discentes da graduação. Monografia: Medianeira, 2013. Disponível em: < http://repositorio.roca.utfpr.edu.br/jspui/bitstream/ 1/2385/1/MD_ENSCIE_III_2012_52.pdf >.

LIMA, A.L.G.S. Um estudo de caso: a criação do Instituto de Biofísica. Anais do XXVI Simpósio Nacional de História - ANPUH. São Paulo, julho 2011 p 1-16

LOPES, E.B.; PONTES, R.M. Técnicas e jogos para trabalhar com grupos. Curitiba, 2000. Disponível

em:<http://www.emater.pr.gov.br/arquivos/File/Bi blioteca_Virtual/Publicacoes_Tecnicas/Metodologi a/Tecnicas_jogos_trabalhar_grupos.pdf $>$.
MANACORDA, M.A. História da Educação: da antiguidade aos nossos dias. São Paulo: Cortez, 1989.

MARTIN, S. Peer-to-peer Teaching in Higher Education: A Critical Literature Review, Mentoring \& Tutoring: Partnership in Learning, 24:2, 124-136, 2016. DOI: $10.1080 / 13611267.2016 .1178963$

MIRANDA, M. Código Pedagógico dos jesuítas: Ratio Studiorum da Companhia de Jesus: Esfera do Caos, 2009.

MOREIRA, C. H. P et al. A biofísica na formação do biólogo e a opinião dos docentes formadores da área. Anais do $16^{\circ}$ Cong. Inter. de Tec. na Educação. ISSN: 1984-6355, Recife. Set de 2018.

POPESCU, A. Teaching biophysics: suggestions for the introductory lecture in Biophysics. Rom. J. Biophys. 2002 12(3-4):129-136. Disponível em: < http://www.rjb.ro/articles/76/aup.htm>.

POPESCU, A. Fundamentals of biophysics (em romeno). vol. Eu, Toda Casa de Edição, Bucareste, 1994.

RIBEIRO, M.L.S. História da educação brasileira: a organização escolar. 20ed. São Paulo: Cortez, 2002.

OSBORN, A. F. Applied Imagination: principles and procedures of creative thinking. New York City: Charles Scribner's Sons, 1957.

TANAKA, J. C.; GLADNEY, L. D. Teaching biophysics: Strategies for recruiting and retaining minorities in physics and biophysics. Biophysical Journal. 1993 65(1): 552-558 